\title{
Hepatite C: avaliar a correlação da resposta virológica na 4ạ semana de tratamento com a resposta virológica sustentada em um hospital terciário no Ceará
}

\section{Hepatitis C: assessing the correlation of the virological response in the $4^{\text {th }}$ week of treatment with the sustained virological response in a tertiary hospital in Ceará}

Cibele Silveira Pinho ${ }^{1}$. Lúcia Libanez Bessa Campelo Braga² ${ }^{2}$ José Milton de Castro Lima ${ }^{3}$. Elodie Bomfim Hyppolito ${ }^{4}$. Flávia Siqueira Furtado Melloํ. Flavio Esmeraldo Rolim ${ }^{1}$. Rodrigo Vieira Costa Lima ${ }^{5}$.

1 Médico(a), Residente do Programa de Gastroenterologia, Universidade Federal do Ceará (UFC), Fortaleza, Ceará, Brasil. 2 Doutora em Gastroenterologia, Chefe e Coordenadora do serviço de Gastroenterologia, Hospital Universitário Walter Cantídio (HUWC). Professora, Universidade Federal do Ceará (UFC), Fortaleza, Ceará, Brasil. 3 Doutor em Gastroenterologia, médico Preceptor do serviço de Gastroenterologia, Hospital Universitário Walter Cantídio (HUWC). Professor adjunto, Universidade Federal do Ceará (UFC), Fortaleza, Ceará, Brasil. 4 Mestrado em Clínica Médica, Serviço de Transplante Hepático, Hospital Universitário Walter Cantidio (HUWC). Hepatologista, Hospital São José, Fortaleza, Ceará, Brasil. 5 Médico Gastroenterologista, Preceptor do serviço de Gastroenterologia, Hospital Universitário Walter Cantídio (HUWC), Fortaleza, Ceará, Brasil.

\section{RESUMO}

Introdução: a hepatite $\mathrm{C}$ acomete aproximadamente $1 \%$ da população brasileira, cronificando em até $80 \%$ dos casos. As novas drogas de ação antivirais diretas (DAAs) aumentaram significativamente a resposta virológica sustentada (RVS), ficando em torno de 90\%, além de reduzirem os efeitos colaterais e a duração da terapia medicamentosa. Em alguns casos, a carga viral já se encontra negativada em torno da quarta semana de tratamento. Objetivo: avaliar a correlação entre a carga viral da $4^{\mathrm{a}}$ semana e a da resposta virológica sustentada (RVS). Método: estudo retrospectivo com uma série de 462 pacientes portadores de hepatite C crônica submetidos ao tratamento com as novas drogas antivirais diretas (DAAs) em dois hospitais terciários da rede pública de saúde do estado do Ceará. Resultado: dos 462 pacientes analisados, 193 foram selecionados para o estudo. 148 pacientes avaliados (76,6\%) apresentaram carga viral indetectável $(<12$ cópias $/ \mathrm{ml})$ na $4^{\mathrm{a}}$ semana de tratamento, sendo que destes $97 \%$ obtiveram a RVS. 42 pacientes $(21,7 \%)$ não negativaram a carga viral ao fim da $4^{\mathrm{a}}$ semana de tratamento, mas apresentaram RVS, e apenas 7 pacientes $(3,6 \%)$ foram considerados como resistentes ao tratamento com o uso das DAAs. Conclusão: a dosagem da carga viral após o primeiro mês do uso dos antivirais mostrou-se confiável na maioria dos casos. Novos estudos devem ser feitos a fim de aumentar a confiança dos resultados, para então utilizá-los como fonte segura de resposta terapêutica.

Palavras-chave: Hepatite C. Antivirais. Viremia.

\section{ABSTRACT}

Background: Hepatitis C affects approximately $1 \%$ of the Brazilian population, chronifying up to $80 \%$ of the cases. The new direct action antiviral drugs (AADs) significantly increased sustained virological response, reaching about $90 \%$, in addition to reduce the side effects and duration of drug therapy. In some cases, the viral load is already negative around the fourth week of treatment. Objective: To evaluate the correlation between week 4 viral load and sustained virological response (SVR). Method: Retrospective study with a series of 462 patients with chronic hepatitis $\mathrm{C}$ undergoing treatment with the new direct antiviral drugs (AADs) in two tertiary hospitals of the public health network in the state of Ceará. Results: Of the 462 patients analyzed, 193 were selected for the study. 148 patients evaluated (76.6\%) had an undetectable viral load $(<12$ copies / ml) in the 4th week of treatment, of which 97\% obtained SVR. 42 patients $(21.7 \%)$ did not negatively affect the viral load at the end of the 4th week of treatment but presented SVR, and only 7 patients (3.6\%) were considered to be resistant to treatment with the use of AADs. Conclusion: The viral load after the first month of antiviral use was reliable in most cases. Further studies should be done to increase confidence in the results and then use them as a safe source of therapeutic response.

Keywords: Hepatite C. Antivirais. Viremia.

Autor correspondente: Cibele Silveira Pinho, Avenida Padre Antônio Tomás, 2200, Aldeota, Fortaleza, Ceará. CEP: 60140-160. Telefone: +55 85 98899-7716. E-mail: cibelespinho@gmail.com

Conflito de interesses: Não há qualquer conflito de interesses por parte de qualquer um dos autores.

Recebido em: 05 Jul 2017; Revisado em: 24 Jan 2018; Aceito em: 11 Mar 2018. 


\section{INTRODUÇÃO}

$\mathrm{O}$ vírus da hepatite $\mathrm{C}$ (VHC) é uma das causas mais comuns de doença hepática crônica no mundo. Estima-se que cerca de 185 milhões de pessoas estejam infectadas pelo VHC, causando cerca de 350.000 mortes por ano, o que representa um importante problema de saúde..$^{1-3}$

A hepatite $\mathrm{C}$ crônica é uma doença insidiosa e que evolui progressivamente para cirrose em $20 \%$ a $50 \%$ dos casos durante um período de 10 a 30 anos. ${ }^{3}$ Além disso, é uma importante causa de hipertensão portal, descompensação hepática e carcinoma hepatocelular. ${ }^{4}$

Em regiões de alta endemicidade, como o sul e sudeste do Brasil, a hepatite viral crônica geralmente responde por mais de $50 \%$ de carcinoma hepatocelular e cirrose. Cerca de $27 \%$ dos casos de cirrose em todo o mundo e $25 \%$ dos casos de carcinoma hepatocelular podem ser atribuíveis à infecção por VHC. ${ }^{5}$

Até recentemente, o tratamento da hepatite $\mathrm{C}$ necessitava do uso de interferon peguilado (PEG) e ribavirina (RBV) e tinha elevada taxa de morbidade, com percentual de cura em torno de $50 \%$. Com a descoberta das novas drogas de ação antivirais diretas (DAAs), ocorreram grandes avanços no tratamento, que aumentaram significativamente a resposta virológica sustentada (RVS), ficando em torno de 85 a 90\% dos casos, além de redução dos efeitos colaterais e da duração do tratamento.,

O objetivo da terapêutica é a cura, definida pela RVS, que se caracteriza pela carga viral indetectável no sangue após 12 semanas do fim do tratamento, estando relacionada a resultados positivos para a saúde, como diminuição da mortalidade por complicações hepáticas ${ }^{8}$. A obtenção de uma resposta virológica rápida (RVR), definida como carga viral indetectável na semana 4 durante o tratamento, é altamente preditiva de resposta virológica sustentada (RVS). ${ }^{9}$

No Brasil, um novo protocolo com diretrizes terapêuticas para a hepatite C e coinfecções foi lançado em 2015, aprovado pelo Ministério da Saúde. ${ }^{10}$

Os números iniciais em vida real demonstraram alto índice de sucesso com o uso das novas drogas, em praticamente todos os genótipos. A terapêutica utilizada varia de acordo com o genótipo do paciente, sendo eles 1, 2, 3 ou 4. As medicações autorizadas pela portaria do Ministério foram os antivirais Sofosbuvir, Daclatasvir e Simeprevir, utilizados por 12 ou 24 semanas, de acordo com as particularidades de cada genótipo e do paciente a ser tratado. ${ }^{10}$

No Hospital Universitário Walter Cantídio, instituição associada à Universidade Federal do Ceará, os tratamentos tiveram início em meados de 2015, após aprovação do novo protocolo. Neste mesmo período, houve início do tratamento de pacientes acompanhados no Hospital São José, referência no tratamento de doenças infecciosas no estado. Desde então, centenas de pacientes que se encaixaram nas indicações foram submetidos ao novo tratamento, com elevados índices de sucesso, compatíveis com outros países e estudos laboratoriais de eficácia.
O objetivo primário do estudo foi analisar a resposta terapêutica na $4^{\mathrm{a}}$ semana e compará-la à resposta virológica sustentada nos pacientes submetidos ao regime terapêutico aprovado em 2015.

\section{MATERIAL E MÉTODOS}

Estudo descritivo, longitudinal e retrospectivo com dados coletados de prontuários médicos de pacientes acompanhados por hepatite C crônica nos ambulatórios de Hepatologia do Hospital Universitário Walter Cantídio, ambulatórios do Serviço de Transplante Hepático do mesmo hospital, e pacientes do Hospital São José de doenças infecciosas. Todos os pacientes foram informados sobre a realização do estudo. $\mathrm{O}$ trabalho foi submetido e aprovado pelo Comitê de Ética local.

Foram incluídos no estudo todos aqueles que realizaram o tratamento completo, e que foram submetidos às dosagens de carga viral na $4^{\mathrm{a}}$ semana de tratamento e após a $12^{\mathrm{a}}$ semana do início do regime terapêutico, no intuito de avaliar a presença de resposta virológica sustentada.

Foram excluídos do estudo aqueles que não haviam concluído o tratamento até o momento da avaliação de dados. O algoritmo de seleção encontra-se na Figura 1.

Figura 1. Seleção de pacientes.

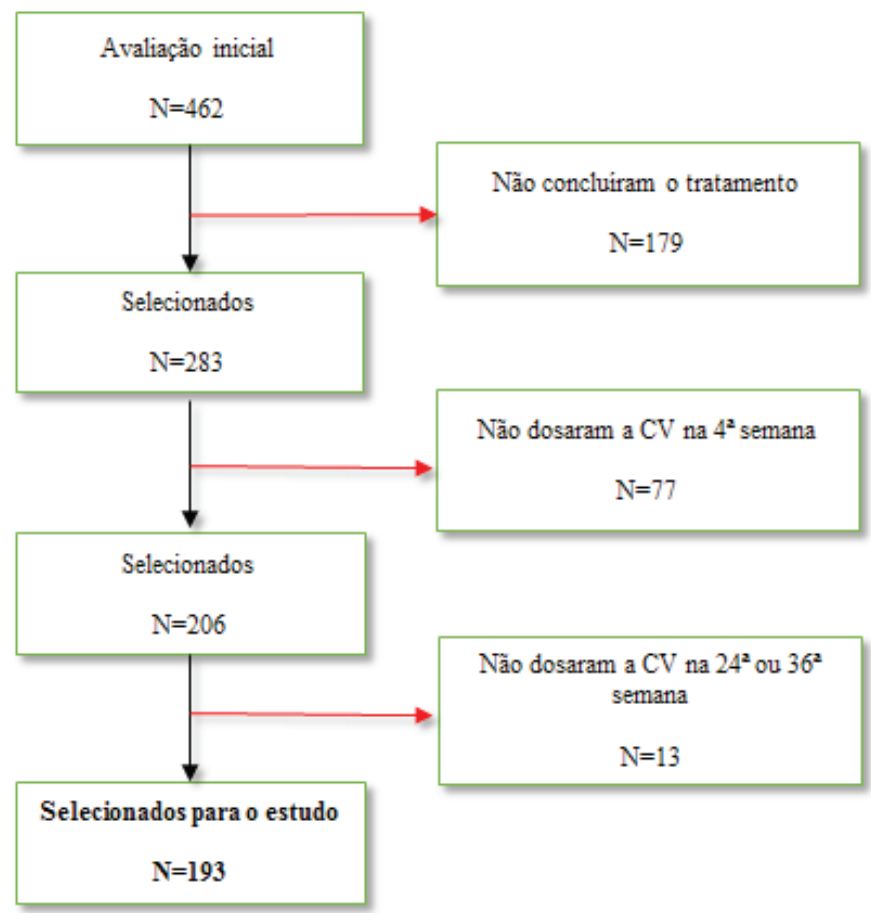

Os pacientes selecionados eram dos genótipos 1, 2 e 3, e abrangiam aqueles virgens de tratamento, bem como experimentados a regimes anteriores que não incluíssem o uso das novas drogas aprovadas pelo protocolo brasileiro.

A maioria dos pacientes selecionados já se encontrava em estágio de cirrose hepática, no entanto, compensada. 
O grau de fibrose foi determinado através de métodos não invasivos, como ARFI, Fibroscan, APRI e FIB4, e também por biópsia hepática com cálculo do escore de METAVIR. De acordo com as diretrizes do Ministério da Saúde, pacientes que se encaixam nos estágios F3 e F4, ou aqueles com grau F2 há mais de 3 anos, são elegíveis para o início do tratamento.

Todos os pacientes foram submetidos a regimes terapêuticos que incluíram associações de Sofosbuvir, Daclatasvir e/ ou Simeprevir, adicionados ou não do uso de Ribavirina, de acordo com cada caso. O tempo de tratamento variou de 12 a 24 semanas.

As dosagens de carga viral foram realizadas antes do início do tratamento, e após 4, 12 e/ou 24 semanas. O método utilizado para dosagem foi o PCR (proteína $\mathrm{C}$ reativa) quantitativo. Pacientes que obtiveram cargas virais negativas (menos de 12 cópias $/ \mathrm{ml}$ ) foram considerados como resposta virológica sustentada, e, portanto, sucesso terapêutico.

Foram considerados como resistentes ao regime aqueles que, ao final de 12 semanas pós-tratamento, ainda apresentavam carga viral positiva (mais de 12 cópias/ml). A segurança e tolerabilidade das drogas foram avaliadas através de consultas periódicas e exames complementares realizados ao longo do período de tratamento.

Os pacientes que apresentaram carga viral detectável ( $>12$ cópias $/ \mathrm{ml}$ ) durante todo o tratamento ou indetectável na $4^{\mathrm{a}}$ e na $12^{\mathrm{a}}$ semana após o fim do tratamento foram considerados "concordantes". Aqueles que apresentaram carga viral detectável em algum momento e indetectável em outro foram considerados "não concordantes".

Os dados foram colocados em planilha do programa Microsoft Excel, e então realizada análise por comparação direta, com criação de tabelas e gráficos para avaliação dos dados.

\section{RESULTADOS}

No total, 462 pacientes submetidos ao tratamento foram analisados. Destes, 179 foram excluídos por ainda estarem em vigência do regime terapêutico, 77 foram excluídos por falta de dosagem da carga viral na $4^{\mathrm{a}}$ semana de tratamento, e ainda, 13 pacientes por ausência de dados quanto à carga viral da $24^{\mathrm{a}}$ ou $36^{\mathrm{a}}$ semana. 193 pacientes foram então selecionados para o estudo (Figura 1).

Em relação à resposta terapêutica, 147 foram considerados "concordantes", enquanto que 46, "não-concordantes". O estudo identificou 7 pacientes resistentes à terapia antiviral, sendo que 3 destes não negativaram a carga viral em nenhum momento e 4 obtiveram carga viral indetectável na $4^{\mathrm{a}}$ semana de tratamento, no entanto não houve resposta virológica sustentada. No total de 144 pacientes $(74,6 \%)$ houve resposta terapêutica confiável na $4^{\text {a }}$ semana, concordando com a RVS. 42 pacientes $(21,8 \%)$, no entanto, apesar da RVS, não negativaram a carga viral (CV) ao fim do primeiro mês de terapia antiviral (Gráfico 1).

Quanto às características epidemiológicas, a maioria dos pacientes foi do sexo masculino $(68,4 \%)$. A média de idade foi de, aproximadamente, 59 anos, $37 \%$ daqueles submetidos ao tratamento já haviam sido transplantados, sendo 71 pacientes submetidos a transplante hepático, e 01 pós-transplante renal. $60 \%$ dos pacientes selecionados já se encontravam em estado de cirrose (grau F4 em métodos de estadiamento). Os dados epidemiológicos encontram-se na Tabela 1.

Em relação ao tratamento, 79,8\% dos pacientes avaliados foram submetidos ao regime de 12 semanas, 59\% eram virgens de tratamento (naive). Quanto ao genótipo, a grande maioria era do genótipo 1 (78,2\% dos pacientes), sendo $2,6 \%$ do genótipo 2 e os restantes $(19,2 \%)$ do genótipo 3. A utilização de Ribavirina associada aos novos antivirais foi instituída em $49 \%$ dos pacientes. Destes, $56 \%$ já haviam sido submetidos a transplante hepático.

Gráfico 1. Resposta terapêutica.

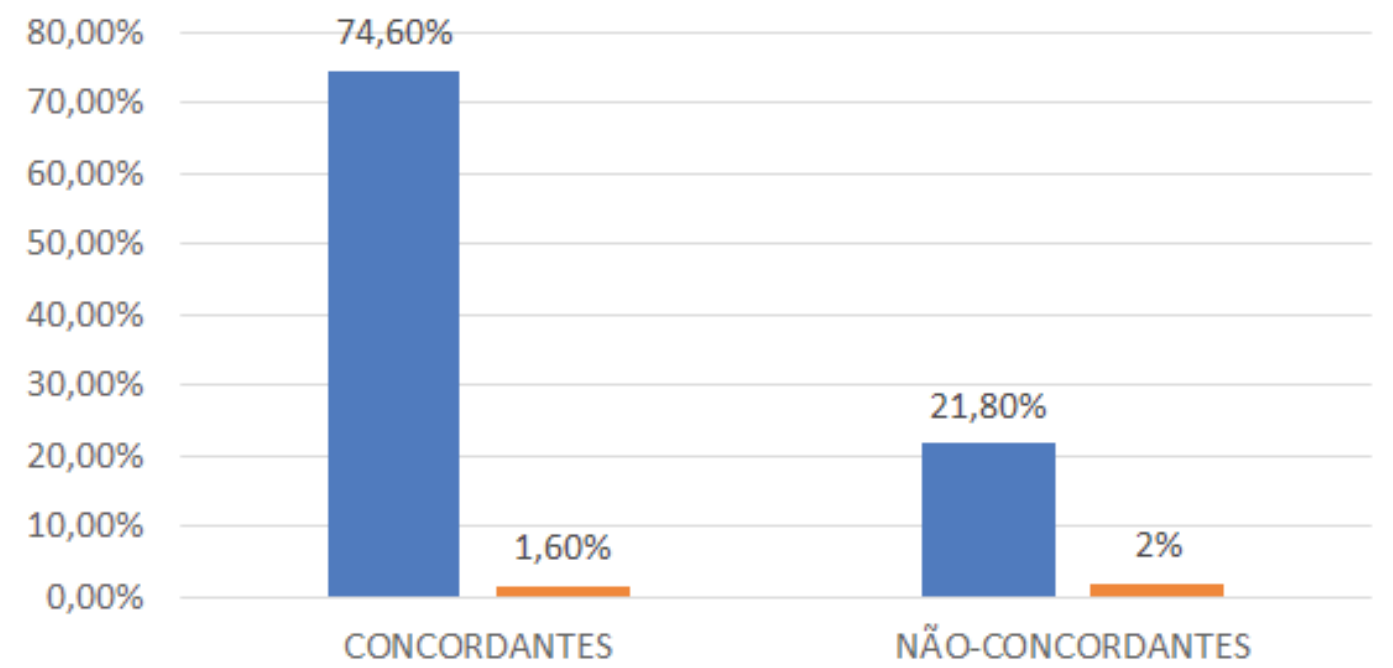

RVS $\quad$ RESISTENTES 
Tabela 1. Dados epidemiológicos.

\begin{tabular}{|c|c|c|c|c|}
\hline & \multicolumn{2}{|c|}{ CONCORDANTES } & \multicolumn{2}{|c|}{ NÃO-CONCORDANTES } \\
\hline & RVS & $\begin{array}{c}\text { FALHA DO } \\
\text { TRATAMENTO }\end{array}$ & RVS & RECIDIVANTES \\
\hline Parâmetros & $\mathrm{n}=144$ & $n=3$ & $\mathrm{n}=42$ & $\mathrm{n}=4$ \\
\hline Idade & 58,4 & 63,3 & 60,7 & 56,5 \\
\hline \multicolumn{5}{|l|}{ Sexo } \\
\hline Masculino (\%) & $99(68,75)$ & $3(100)$ & $28(66,66)$ & $3(75)$ \\
\hline Feminino (\%) & $45(31,25)$ & $0(0,0)$ & $14(33,33)$ & $1(25)$ \\
\hline \multicolumn{5}{|l|}{ Status de Fibrose } \\
\hline F1/F2 (\%) & $58(40,30)$ & $1(33,33)$ & $17(40,47)$ & $2(50)$ \\
\hline F3/F4 (\%) & $86(59,70)$ & $2(66,66)$ & $25(59,53)$ & $2(50)$ \\
\hline \multicolumn{5}{|l|}{ Tratamentos prévios } \\
\hline Virgem (NAIVE) (\%) & $87(60,41)$ & $2(66,66)$ & $22(52,38)$ & $3(75)$ \\
\hline Experimentado (\%) & $57(39,59)$ & $1(33,33)$ & $20(47,62)$ & $1(25)$ \\
\hline \multicolumn{5}{|l|}{ Tempo de tratamento } \\
\hline 12 semanas $(\%)$ & $111(77,08)$ & $3(100)$ & $36(85,71)$ & $4(100)$ \\
\hline 24 semanas $(\%)$ & $33(22,91)$ & $0(0,0)$ & $6(14,29)$ & $0(0,0)$ \\
\hline \multicolumn{5}{|l|}{ Transplante hepático } \\
\hline Não-transplantado & $91(63,2)$ & $2(66,66)$ & $26(61,90)$ & $3(75)$ \\
\hline Transplantado & $53(36,8)$ & $1(33,33)$ & $16(38,10)$ & $1(25)$ \\
\hline
\end{tabular}

Dos pacientes selecionados, 3,62\% apresentaram resistência ao regime terapêutico (total de 7 pacientes). Todos os que apresentaram resistência eram cirróticos, com classificação de Child-Pugh entre A e B. 4 pacientes $(66 \%)$ eram do genótipo 3, e $71 \%$ virgens de tratamento. $71 \%$ utilizaram Ribavirina no esquema terapêutico. Todos os pacientes resistentes que haviam sido experimentados previamente utilizaram o esquema com Interferon peguilado e Ribavirina, sem uso documentado de outros antivirais.

Em relação à segurança de uso, as drogas foram, em geral, bem toleradas. Os efeitos adversos mais relatados foram cefaleia $(24 \%)$ e fadiga (14\%). Anemia importante foi evidenciada em alguns pacientes, presumivelmente mais associada ao uso de Ribavirina.

\section{DISCUSSÃO}

A hepatite $\mathrm{C}$ tem passado por um grande avanço quanto ao sucesso terapêutico em pacientes portadores crônicos da doença, e as novas drogas aprovadas para uso pelo MS desde 2015 têm aumentado em grande escala os índices de sucesso terapêutico, bem como diminuído a incidência dos efeitos colaterais.

Nossos dados foram compatíveis com os descritos na literatura. Obtivemos 96,4\% de RVS e apenas a análise após realização de tratamento da hepatite $\mathrm{C}$ com os novos DAAs evidenciou altos índices de sucesso quanto a RVS, visto que $96,4 \%$ dos pacientes apresentaram carga viral negativa após 12 semanas do fim do tratamento. Apenas 7 pacientes $(3,6 \%)$ apresentaram falha de resposta. Tal número é consistente com os dados da literatura internaciona ${ }^{10}$ de eficácia dos novos antivirais, com o benefício adicional da redução importante na incidência de eventos adversos, alguns inclusive fatais, que ocorriam com os tratamentos anteriores.

A RVR foi alcançada em 148 pacientes $(76,6 \%)$, com carga viral indetectável ao final do primeiro mês de tratamento. Destes, apenas 4 pacientes não obtiveram a RVS, o que refletiu em um índice de 97,3\% de concordância entre a RVR e a RVS. Segundo dados da literatura, a taxa de RVS variou de $88 \%$ a $100 \%$ nos pacientes com RVR, concordando com os números do presente estudo. ${ }^{9}$ Notavelmente, a RVR gerou maior índice de chance para prever a RVS.

A grande maioria dos pacientes que apresentaram falha eram do genótipo 3, um genótipo que ainda apresenta desafios no alvo terapêutico. ${ }^{9}$ No Brasil, o regime inicial indicado para tais pacientes ainda inclui o uso de Interferon peguilado associado a Sofosbuvir e Ribavirina. Aqueles que tem contraindicações ao uso de Interferon são então submetidos ao esquema com Sofosbuvir e Daclatasvir. Nenhum dos pacientes avaliados neste estudo fizeram uso de Interferon. Os protocolos americano e europeu já incluem a combinação de Sofosbuvir e Daclatasvir como primeira escolha para o tratamento de pacientes do genótipo $3^{7}$ e ampliando o tempo de tratamento para 24 semanas, como tem sido proposto pela Sociedade Brasileira de Hepatologia e Sociedade Brasileira de Infectologia, e que se encontra em fase de consulta pública pelo MS. Em conclusão, a hepatite $\mathrm{C}$ tem passado por um grande salto quanto ao sucesso terapêutico em pacientes portadores crônicos da doença, e as novas drogas aprovadas para uso desde 2015 tem aumentado em grande escala os 
índices de resposta virológica sustentada. Uma minoria dos pacientes não responde ao uso desses novos DAAs, e estudos que avaliam polimorfismos existentes no alvo dos novos antivirais já estão sendo realizados ao redor do mundo, na tentativa de descobrir-se outros mecanismos de erradicação do vírus.

\section{REFERÊNCIAS}

1. Kohli A, Osinusi A, Sims Z, Nelson A, Meissner EG, Barrett LL, et al. Virological response after 6 week triple-drug regimens for hepatitis C: a proof-of-concept phase 2A cohort study. Lancet. 2015;385:1107-13.

2. Arase Y, Suzuki F, Suzuki Y, Akuta N, Kobayashi M, Kawamura Y, et al. Sustained virological response reduces incidence of onset of type 2 diabetes in chronic hepatitis C. Hepatology. 2009;49(3):739-44.

3. Thornton K, Deming P, Manch RA, Moore A, Kohli A, Gishet R, et al. Is response guided therapy dead? Low cure rates in patients with detectable hepatitis $\mathrm{C}$ virus at week 4 of treatment. Hepatol Int. 2016;245(3):527-38.

4. Meer AV, Veldt BJ, Feld JJ, Wedemeyer H, Dufour JF, Lammert $\mathrm{F}$, et al. Association between sustained virological response and allcause mortality among patients with chronic hepatitis $\mathrm{C}$ and advanced hepatic fibrosis. JAMA. 2012;308(24):2584-93.

5. Lawitz EJ, Membreno FE. Response-guided therapy in patients with genotype 1 hepatitis $\mathrm{C}$ virus: current status and future prospects. J Gastroenterol Hepatol. 2014;29(2):1574-81.
Os dados de revisão dos prontuários dos pacientes submetidos ao tratamento em nossas instituições mostram uma taxa de sucesso compatível com outros centros. ${ }^{9}$ Novos estudos, no entanto, devem ser realizados no intuito de aumentar a confiança nestes dados para, então, utilizá-los como fonte confiável de resposta terapêutica mesmo antes do término do tratamento.

6. Najafzadeh M, Andersson K, Shrank WA, Krumme AA, Matlin OS, Brennan T, et al. Cost-effectiveness of novel regimens for the treatment of hepatitis C virus. Ann Intern Med. 2015;162:407-19.

7. American Association for the Study of Liver Diseases; Infectious Diseases Society of America. Recommendations for testing, managing, and treating hepatitis C [Internet]. [place unknown: publisher unknown; date unknown] [Acesso em: 25 Nov 2017]. Disponível em: https://www.hcvguidelines.org/

8. Webster DP, Klenerman P, Dusheiko GM. Hepatitis C. Lancet. 2015;385(9973):1124-35.

9. Fried MW, Hadziyannis SJ, Shiffman ML, Messinger D, Zeuzem S. Rapid virological response is the most important predictor of sustained virological response across genotypes in patients with chronic hepatitis C virus infection. J Hepatol. 2011;55(1):69-75.

10. Brasil. Ministério da Saúde. Secretaria de Vigilância em Saúde. Departamento de DST, Aids e Hepatites Virais. Protocolo clínico e diretrizes terapêuticas para hepatite $\mathrm{C}$ e coinfecções. Brasília: Ministério da Saúde; 2015. 88p.

\section{Como citar:}

Pinho CS, Braga LL, Lima JM, Hyppolito EB, Mello FS, Rolim FE, et al. Hepatite C: avaliar a correlação da resposta virológica na 4 a semana de tratamento com a resposta virológica sustentada em um hospital terciário no Ceará. Rev Med UFC. 2018 jul-set;58(3):54-58. 